\title{
Teaching Effect of Contrasting Intonation Systems*
}

\author{
Hanako Hosaka \\ Tokai University, Kanagawa Prefecture, Japan
}

\begin{abstract}
Not many language learners have been taught the sound system systematically. Intonation is no exception. This paper aims to show the effectiveness of contrasting TL (target language) and L1 (first language) intonation systems for the learners to become aware of the TL intonation system as something new and different from what they are familiar with. The Japanese-speaking subjects showed a better understanding of the English intonation system after the instruction on the functions of the five-tone choices in English speech. While they were "aware" of "intonation" as a phenomenon, they did not know "how intonation works", nor were very aware of any differences between TL intonation and the intonation they are familiar with, such as L1 and mother tongues. Therefore, it is better not only to teach the technical rules in intonation, but also to develop the ability to use intonation in TL appropriately in context. Teaching TL intonation system by contrasting with L1 can help the learners to systematically learn how intonation works in TL.
\end{abstract}

Keywords: contrast, teaching effect, intonation system, English, Japanese

\section{Introduction}

It is not always easy for language learners to get the idea of the intonation system in other languages, and it is rarely the case that language learners have been taught the sound system systematically. For example, most of the English major students enrolled in the author's "Introductory Phonetics Course” say that they had never learned the English sound system before the enrolment, and that they wished they had learned it earlier. Likewise, Nakagawa (1996, pp. 106, 115) pointed out that not many learners of Japanese have learned the Japanese sound system including accent and intonation, and she hoped for developing systematic teaching materials for the Japanese sound system. This paper shows that contrasting two intonation systems between TL (target language) and L1 (first language) is effective for the learners to become aware of the "new" intonation system they are acquiring.

The author applies the Discourse Intonation Model (Brazil, 1985, 1994; hereafter DI Model) to both English and Japanese to make a fair contrast. The DI Model is originally designed to capture the "communicative value" of intonation in English discourse contexts. It can be considered as a way of investigating intonation in the discourse analysis framework, looking at "the meaning of intonation" (Brazil, 1997, p. ix) functionally in a stream of natural speech. As shown in Hosaka (2004b, p. 207), the DI Model (originally proposed for English) is

\footnotetext{
* Acknowledgements: The author would like to acknowledge Prof. Yoshihiro Nishimitsu for his various kinds of contributions in the linguistics fields. His flexible approach and the idea of contrast in language have influenced the author in pursuing sound studies and applied linguistics.

Hanako Hosaka, associate professor, Department of English, School of Letters, Tokai University.
} 
suitable in describing oral data in Japanese, as well as variations in L1/L2 (second language) English. Also Yamato (2000) evaluated the DI model as "the most appropriate system to utilise for intonation teaching", because it "focuses on communication and discourse, as well as holding the balance in terms of simplicity of notation system", whereas other existing intonation theories "focus on linguistic descriptions" (pp. 98-99). Hence, the author considers that it is possible to teach the basic patterns of discourse intonation in English to Japanese EFL (English as a foreign language) learners with the DI model.

In this study, the author gave a lesson focusing on the usage of Brazil's five different tone choices in English to Japanese EFL learners at the undergraduate level, and introduced them to the differences of the tones and their meanings while letting them imagine their use of intonation in Japanese. For the purpose of teaching the basic intonation patterns, the author focused on the use of TUs (tone units) with one lexical item (e.g., "yes" and "well”) in context, and then let the students use the five tones in a little longer TUs. This method is motivated on the three points (Hosaka, 2004a, p. 13): (1) The pronunciation of lexical items needs to be dealt with in the stream of speech as well as in citation forms (as shown in dictionaries with International Phonetic Alphabets); (2) It is helpful to be aware of the L1 tendencies in discourse intonation at the lexical level (in comparison to TL tendencies); and (3) Non-native speakers can become aware of the communicative usage of TL intonation through appropriate instructions.

The author compared the students' tone transcriptions before and after the lesson, and analyzed the effect of the lesson. This paper discusses the following points: (1) comparison between English and Japanese intonation systems; (2) teaching of basic English intonation to Japanese EFL learners by comparing the five different tone choices; and (3) the effect of teaching the English intonation system in contrast with the Japanese system.

This paper aims to show the effectiveness of the contrastive approach between TL and L1 in L2 acquisition and foreign language teaching.

\section{Comparison Between English and Japanese Intonation}

\section{Characteristics of English and Japanese Intonation in Contrast}

In both English and Japanese, the intonation system helps to add an "extra" meaning to the original dictionary meaning. We acquire it very early in the L1 acquisition process. According to Ogura (2005, pp. 32-35), from around five months before birth, fetuses can recognize patterns in intonation and stress from the mothers' speech through the amniotic fluid; and infants' babbling starts sounding with intonation after 0;10. According to Cruttenden (1979, as cited in Suganuma, 1993, pp. 5, 19), a child starts to discriminate and produce differences in pitches, loudness, length of sound, and voice qualities from neonates, and "during the one-word stage or early in the two-word stage he may begin to use the difference between a falling and a rising pitch pattern systematically” (p. 19). According to Guernsey's (1928) research on 200 infants from 0;2 to 1;9 (as cited in Murata, 1968, p. 23), the influence of L1 discourse appears in infants' intonation long before their speech starts sounding like L1. Since then they usually use it unconsciously in their L1 speech.

This means that L1 intonation would easily stay as part of the core of the "new" language system. Intonation is more likely to cause language transfer from L1 to TL (= L2) (Hosaka, 1996a, 1996b).

Because of this aspect, the author considers it is effective to make a clear contrast between TL and L1 in teaching TL, so that the learners can utilize the awareness of the TL-L1 contrast in using TL. 
As for five-tone choices in the DI Model, while the majority of English tone use is p, r+, r, and o tones, that of Japanese tone use is $\mathrm{p}, \mathrm{r}+$, and o tones. Table 1 shows an example of tone choices in English and Japanese: Both languages have similar systems, with different frequencies in tones.

Table 1

Example of Tone Choices in English and Japanese (Percentages of Each Tone Choice Frequency) ${ }^{1}$

\begin{tabular}{|c|c|c|c|c|c|c|}
\hline \multicolumn{2}{|l|}{$\begin{array}{l}\text { English } \\
\text { // it is RAINing // (\%) }\end{array}$} & \multicolumn{3}{|c|}{ Brazil's five-tone choices } & \multicolumn{2}{|c|}{$\begin{array}{l}\text { Japanese } \\
\text { // Ame desu ka // (\%) }\end{array}$} \\
\hline It is raining! (surprise, unexpected) & 0.3 & $\mathrm{p}^{+}$ & rise-fall & $\wedge$ & 0.1 & It is raining! (surprise, unexpected) \\
\hline It is raining. (statement) & 47.8 & $\mathrm{p}$ & fall & 1 & 74.5 & It is raining. (statement) \\
\hline $\begin{array}{l}\text { It is true it is raining. (expected and } \\
\text { not interested) }\end{array}$ & 11.3 & o & level & - & 16.0 & It is raining... (expected and not interested) \\
\hline Is it raining? & 30.5 & $\mathrm{r}^{+}$ & rise & / & 6.2 & Is it raining? \\
\hline \multirow[t]{2}{*}{ Is it really raining? } & 6.4 & $\mathrm{r}$ & fall-rise & V & 2.1 & Is it raining? (more involved) \\
\hline & & & & & & $\begin{array}{l}\text { Cf. // aME desu ka // } \\
(=\text { candy })^{2}\end{array}$ \\
\hline
\end{tabular}

Note. Adapted from Hosaka, 2004b, p. 206.

Table 2 is the summary of the characteristics of English and Japanese intonation (Hosaka, 2004b, p. 203).

Table 2

Intonational Comparison Between English and Japanese

\begin{tabular}{|l|l|l|}
\hline English & & Japanese \\
\hline Indo-European & Group & Non-Indo-European \\
\hline SVO (Subject+Verb+Object) & Word order & SOV (Subject+Object+Verb) \\
\hline $\begin{array}{l}\text { Intonation language } \\
\text { (determined by discourse structure) } \\
\text { intonation + rhythm } \\
\text { intonation > accent }\end{array}$ & Typology & $\begin{array}{l}\text { Word-pitch language } \\
\text { (determined by word accent structure) } \\
\text { accent + pause } \\
\text { accent > intonation }\end{array}$ \\
\hline $\begin{array}{l}\text { Prosodic \& discoursal unit } \\
\text { At least 1 primary accent } \\
\text { (optionally with pause and/or lengthening) }\end{array}$ & TU & $\begin{array}{l}\text { Prosodic \& pausing unit } \\
\text { Boundary low tone + pause } \\
\text { (often with pragmatic particles) }\end{array}$ \\
\hline $\begin{array}{l}\text { Discoursally various } \\
\text { Primarily for intonation purposes }\end{array}$ & $\begin{array}{l}\text { Intonation patterns } \\
\text { Fall = certainty } \\
\text { Rise = uncertainty } \\
\text { Level = continuation }\end{array}$ & Fairly fixed \\
\hline $\begin{array}{l}\text { "stress accent” } \\
\text { movable } \\
\text { depending on intonation and rhythm }\end{array}$ & Pitch & Mainly for accentual purposes \\
\hline
\end{tabular}

Note. Adapted from Hosaka, 2004b: based on Hosaka, 1996a, 1996b, cf. Cruttenden, 1986; Kubozono, 1995; Beckman \& Pierrehumbert, 1986.

As in Tables 1-2, it is possible to contrast the intonation systems of the two languages in the same DI Model. In addition, using the same model, it becomes easier to show the similarities and differences in the intonation system in different languages: in this case, teaching English to Japanese EFL learners.

\footnotetext{
1 The frequencies of each tone choice were analyzed in Hosaka (in progress) in the context of reading aloud. The total of the five tones in Table 1 does not make 100\%, because 3.7\% in the English data and 1.1\% in the Japanese data did not have clear tones to be uniquely identified as one of them.

${ }^{2}$ In Japanese, it is possible to distinguish meanings solely by the use of prominence in speech, as in // Ame // (rain) and // aME // (candy). This is similar to the distinction of // CONduct // (noun form) and // conDUCT // (verb form) in English.
} 
The author considers the systematic teaching of intonation would help the L2 learners become more aware of the "new" intonation system in TL.

\section{Research Questions}

In the author's other ongoing research in teaching listening in English to Japanese EFL learners, she found as follows: (1) Japanese EFL learners tend to be aware of their difficulty in "listening”; and (2) Nearly half of them can be successfully improved their listening skill in English by instruction in how to listen.

The research questions in this paper are: Could the same logic apply to teaching intonation? If we give the students instruction on English intonation systematically, would it improve their listening skill?

\section{Teaching Basic English Intonation to Japanese EFL Learners by Contrasting the Five Different Tones}

\section{Subjects}

The author gave a lesson on the basic English intonation system with focus on the five tones as in Table 1 to the total of 64 Japanese students in four regular English language classes for undergraduate focused on listening. The subjects were undergraduate Japanese EFL learners at two Japanese universities. Their English levels varied to some extent, mostly in the range of low- to high-intermediate. The author compared their tone choice perception at between pre- and post-instruction.

\section{Teaching the English Tone Choice System}

In order to teach the tone choices, the author made a set of handouts (based on Utsu \& Schaefer, 1989/2001, pp. 30-36; Brazil, 1994, 1997; Bradford, 1988) as a teaching material. She designed it as one lesson to cover the five-tone differences in context sound-wise and meaning-wise. For data collection in this lesson, the author included a short dialogue in the handouts. Considering the subjects’ English level, the dialogue contains only p ( $)$ and $\mathrm{r}+(/)$ tones in the context, which are common in Japanese intonation as well.

The procedure of the English tone choice lesson goes as follows: (1) introduction of the five-tone choices in English. The author introduced each pitch move pattern and the simplified codes to transcribe it (using arrow signs to mark pitch moves); (2) explanation of the basic contrast between English and Japanese intonation; (3) listening to the model dialogue [ $\rightarrow$ Pre-instruction]. The subjects listen to a short model conversation between a man and his wife, and try to transcribe the tones used in this dialogue ${ }^{3}$; (4) comparison of a simple dialogue with different tone choices. They are asked to compare a dialogue between A and B, and imagine how A would answer in the given different situations; (5) learning the differences in the use of intonation. Continued from (4), the handout presents the differences in the use of intonation — each tone and its meaning; (6) prosodic introduction to the five different tones in English. The author reads the same lexical item in the five different tones. The subjects focus on the tones and transcribe each tone; (7) guessing their meanings or functions. They are asked to guess the meaning or function of each tone; (8) explanation in context. The handout explains meanings for each tone in the same context; and (9) reviewing the model dialogue [ $\rightarrow$ Post-instruction]. They listen to the same dialogue again, and transcribe the tones ${ }^{4}$.

\footnotetext{
${ }^{3}$ In Pre-instruction, the author told the subjects, "Listen to the following conversation between a man and his wife. Try to transcribe the tones used in this conversation". Then in Post-instruction, "Listen to the following conversation between a man and his wife AGAIN. Transcribe the tones used in this conversation”.

${ }^{4}$ See the third footnote.
} 
The data in this study are the two attempts in tone transcription of the model dialogue by the subjects in the lesson, i.e., Pre-instruction and Post-instruction ((3) and (9) above).

\section{Results: Transcribing the Five-Tone Choices}

\section{Model Dialogue Used in the Data Collection}

As described earlier, the subjects were asked to try transcribing the tones used in the model dialogue as the data source material before and after the instruction on the basic English intonation system. The author asked them to write the tones using arrow signs, so they could easily visualize what they heard in the context.

The model dialogue used in the lesson (added the DI transcription on the original dialogue used in Utsu \& Schaefer, 1989/2001, p. 31):

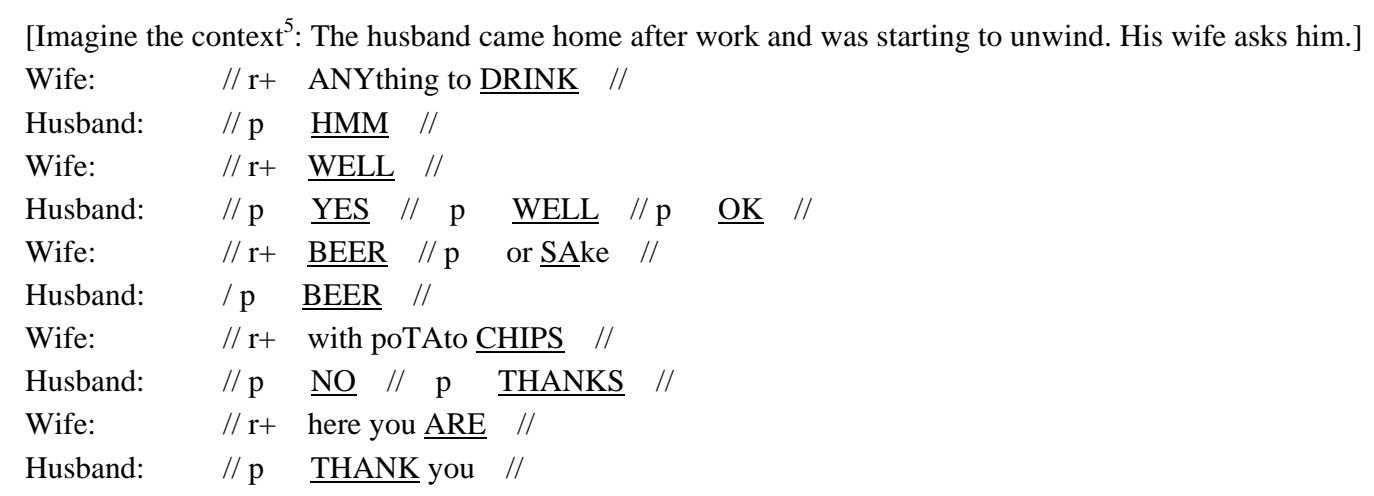

The model dialogue has $14 \mathrm{TUs}^{6}$. It is consisted of only p (fall) and $\mathrm{r}+$ (rise) tones as for the tone choices. Hence, the subjects' attempts were to tell which tone out of the five choices was used in each TU in the model dialogue as they listened.

\section{Pre-instruction Result}

Table 3 is the pre-instruction result of the subjects' attempt of transcribing the tone choice in the model dialogue. The dark-shaded columns are the correct transcription of the tone used in each TU. The bold numbers are the most preferred tone transcription by the subjects.

The findings from Table 3 are: (1) Nearly half of the subjects successfully transcribed in most of the TUs; (2) When the p tone was used, most of the subjects guessed it was either $\mathrm{p}^{+}$, p, or o; (3) When the $\mathrm{r}+$ tone was used, most of them guessed it was either $\mathrm{r}$ or $\mathrm{r}+$; (4) In spite that there was no o tone used in the model dialogue, all of the TUs expect 1 in Table 3 had quite a few subjects guessed as the o tone (e.g., 9, 11, 12 in Table 3); and (5) Although $\mathrm{p}^{+}$and $\mathrm{r}$ rarely occur in English as Table 2 shows, the subjects could not seem to tell them well (e.g., 6 and 8 for $\mathrm{p}^{+}, 3$ and 13 for $\mathrm{r}$ in Table 3).

These findings reflect the Japanese tone preference in Table 1 as follow:

Tone preference (based on Table 1)

\footnotetext{
${ }^{5}$ The original textbook shows the context in a picture.

6 In Discourse Intonation Model, a "TU”, transcribed between a set of double slashes, is used as the unit in intonation including one tone choice occurred in one of the prominences. Brazil (1997) stated it as "the stretch of language that carries the systemically-opposed features of intonation" (p. 3). This is equivalent to "intonation unit" in other intonation theories.
} 
Japanese: $\mathrm{p}(3 / 4)>\mathrm{o}(1 / 6)>\mathrm{r}^{+}(1 / 15)>\mathrm{r} \quad>\mathrm{p}^{+}$.

English: $p(1 / 2)>r+(1 / 3)>0(1 / 10)>r(1 / 15)>p^{+}$.

Hence, the default tone choice for Japanese EFL learners would be p or o, while they are supposed to learn the English way of using each tone.

Table 3

Pre-instruction Attempt of Transcribing the Tone Choices in the Model Dialogue

\begin{tabular}{|c|c|c|c|c|c|c|c|}
\hline No. & TUs & Tone used & $\mathrm{p}^{+}(\wedge)$ & $\mathrm{p}(\backslash)$ & $\mathrm{o}\left(\_\right)$ & $r(V)$ & $\mathrm{r}+(/)$ \\
\hline 1 & // anything to drink? // & $\mathrm{r}^{+}$ & & & & 18 & 45 \\
\hline 2 & // hmm. // & $\mathrm{p}$ & 12 & 40 & 8 & 1 & 2 \\
\hline 3 & // well? // & $\mathrm{r}^{+}$ & 1 & & 1 & 25 & 34 \\
\hline 4 & // yes. // & $\mathrm{p}$ & 7 & 30 & 17 & 1 & 4 \\
\hline 5 & // well, // & $\mathrm{p}$ & 10 & 30 & 21 & & 1 \\
\hline 6 & // OK. // & $\mathrm{p}$ & 22 & 23 & 13 & 2 & 3 \\
\hline 7 & // beer // & $\mathrm{r}^{+}$ & & 6 & 8 & 14 & 34 \\
\hline 8 & // or sake? // & $\mathrm{p}$ & 23 & 19 & 2 & 4 & 13 \\
\hline 9 & // beer. // & $\mathrm{p}$ & & 22 & 32 & & 8 \\
\hline 10 & // with potato chips? // & $\mathrm{r}^{+}$ & & & 2 & 15 & 45 \\
\hline 11 & // no, // & $\mathrm{p}$ & & 4 & 43 & & 12 \\
\hline 12 & // thanks. // & $\mathrm{p}$ & 2 & 32 & 25 & & \\
\hline 13 & // here you are. // & $\mathrm{r}^{+}$ & 4 & 7 & 12 & 26 & 12 \\
\hline 14 & // thank you. // & $\mathrm{p}$ & 13 & 25 & 18 & & 5 \\
\hline
\end{tabular}

Note. Only the valid answers are counted in this table.

\section{Pre-instruction vs. Post-instruction}

Figure 1 is the comparison of the numbers of the subjects according to the numbers of correct answers in the 14 TUs in the model dialogue between Pre- and Post-instruction. The data include all the 64 subjects, including four of those marked as n/a because of no answers written down in either Pre- or Post-instruction. The result is categorized into four score groups according to the numbers of correct answers out of 14 TUs as follow:

Four-score groups: score $0-3$, score $4-6$, score 7 to 10 , score 11 to 14

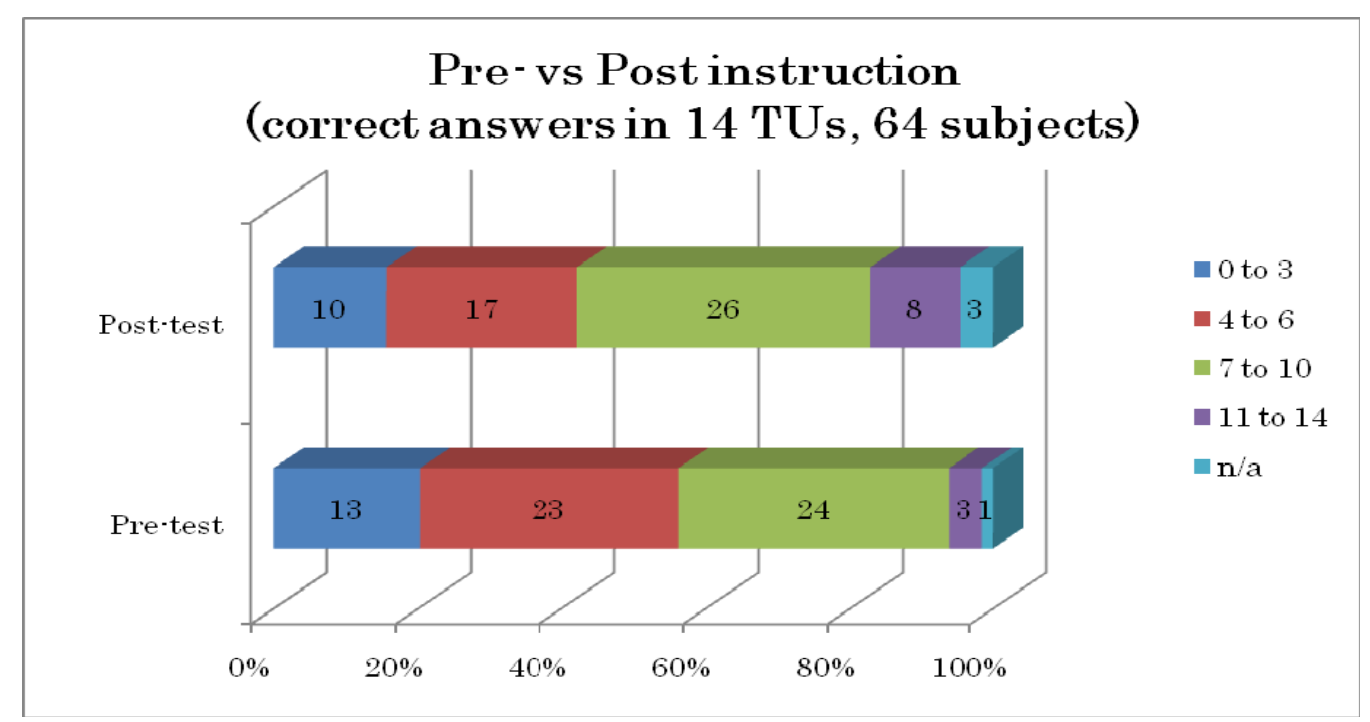

Figure 1. Pre- vs. Post-instruction result (counted by the number of subjects). 
Figure 1 shows the lower-score groups became smaller (from $56 \%$ to $42 \%$ ), and the higher-score groups became larger (from $42 \%$ to 53\%). This means even one lesson concentrated on intonation was effective.

\section{Teaching Effect Comparison According to the Score in Pre-instruction}

The author categorized the teaching effect by comparing each subject's Pre-instruction answer with its Post-instruction answer per each TU as in Table 4.

Table 4

The Teaching Effect Categories Used in the Analysis

\begin{tabular}{|l|l|l|l|}
\hline Teaching effect & Pre-instruction & Post-instruction & Explanation \\
\hline Positive & Incorrect & Correct & Improved after instruction \\
\hline \multirow{2}{*}{ Neutral } & Correct & Correct & \multirow{2}{*}{ No change after instruction } \\
\cline { 2 - 3 } & Incorrect & Incorrect & Got worse after instruction \\
\hline Negative & Correct & Incorrect & INVALID to show the effect \\
\hline n/a & n/a in either or both of Pre- and Post-instruction &
\end{tabular}

Figure 2 is the teaching effect in total counted by the number of TUs (out of 840 TUs $=14$ TUs $x 60$ valid subjects), using the four categories above. When counted by the numbers of TUs, $22 \%$ of the TUs (181 out of 840) showed positive effect. It is notable that $11 \%$ showed negative effect, probably because the subjects might have confused until they would fully digest the new knowledge of tone choices.

\section{Teaching effect in total by \# of TUs}

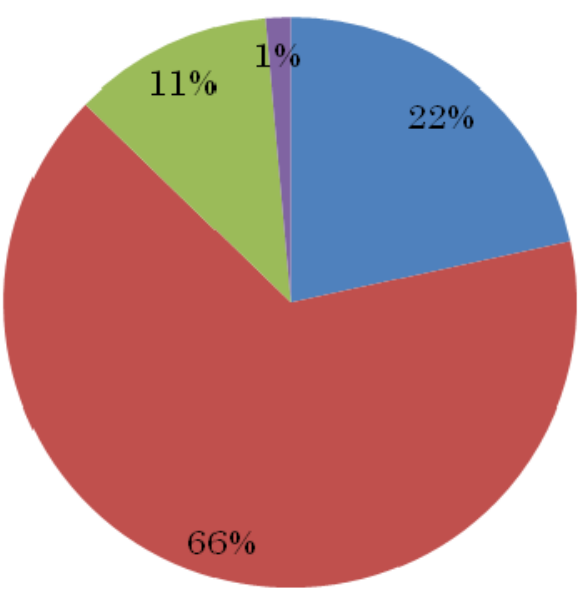

positive

neutral

negative

$\mathrm{n} / \mathrm{a}$

Figure 2. Teaching effect in total (counted by the number of TUs).

Figure 3 is the teaching effect in total (counted by the number of TUs out of 840 TUs) compared by the score groups as in "Four-score groups: score 0-3, score 4-6, score 7 to 10, score 11 to 14 ", using the four categories in Table 4. The top "total" bar is the same as in Figure 2, as reference to each score group.

Figure 3 indicates: (1) All the four-score groups show similar tendencies in teaching effect; (2) The lower-score groups show more of positive teaching effect (24\% in $0-3,26 \%$ in $4-6,18 \%$ in $7-10$, and $10 \%$ in 11-14); and (3) The higher-score groups show less of positive effect, and a little more negative effect instead (7\% in $0-3,12 \%$ in $4-6,13 \%$ in $7-10$, and $14 \%$ in $11-14$ ). 


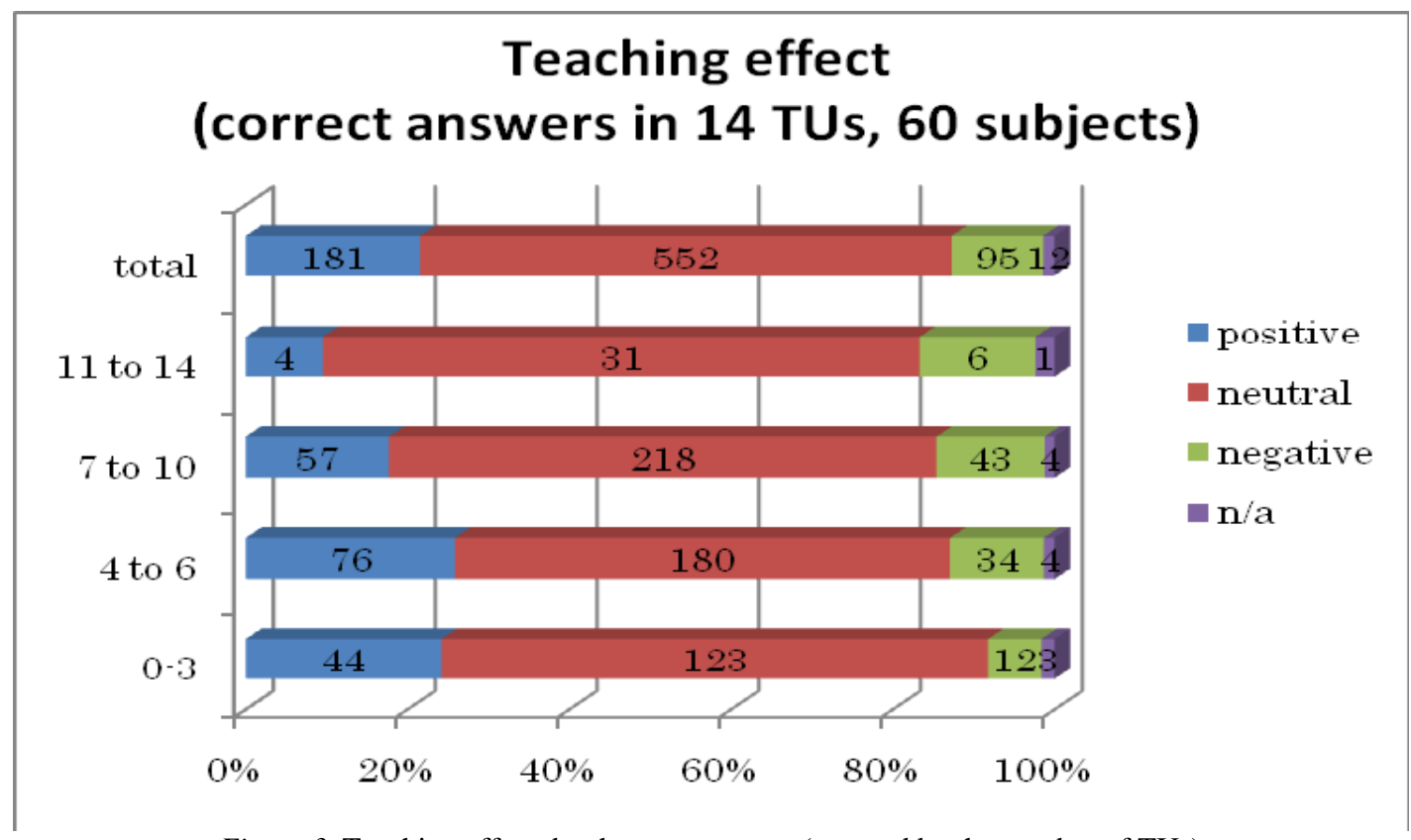

Figure 3. Teaching effect: by the score groups (counted by the number of TUs)

Therefore, from Figures 2-3, even one lesson concentrated on intonation had positive teaching effect in 22\% of the TUs in all the valid subjects, and the positive effect was bigger in the lower-score groups. On the other hand, $11 \%$ of the TUs showed negative effect, and it was slightly bigger in the higher-score groups. This implies overt intonation instruction may be more effective in lower intermediate level.

\section{Teaching Effect Comparison Between $p$ and $r+$ Tones}

In the 14 TUs in the model dialogue (3), there are nine p TUs and five $r+$ TUs. The author presents Figures 4-5 to compare the teaching effect between $\mathrm{p}$ and $\mathrm{r}+$.

Figure 4 is the teaching effect compared between p vs. $r+$ tones counted by the number of TUs. In Figure 4 , the author counted only the correct answers, and the numbers of correct answers increased in both $\mathrm{p}$ and $\mathrm{r}+$ tones after instruction (i.e., $8.5 \%$ increase $(38.1 \% \rightarrow 46.6 \%)$ in p TUs, $11.3 \%$ increase $(49.0 \% \rightarrow 60.3 \%)$ in $r+$ TUs).

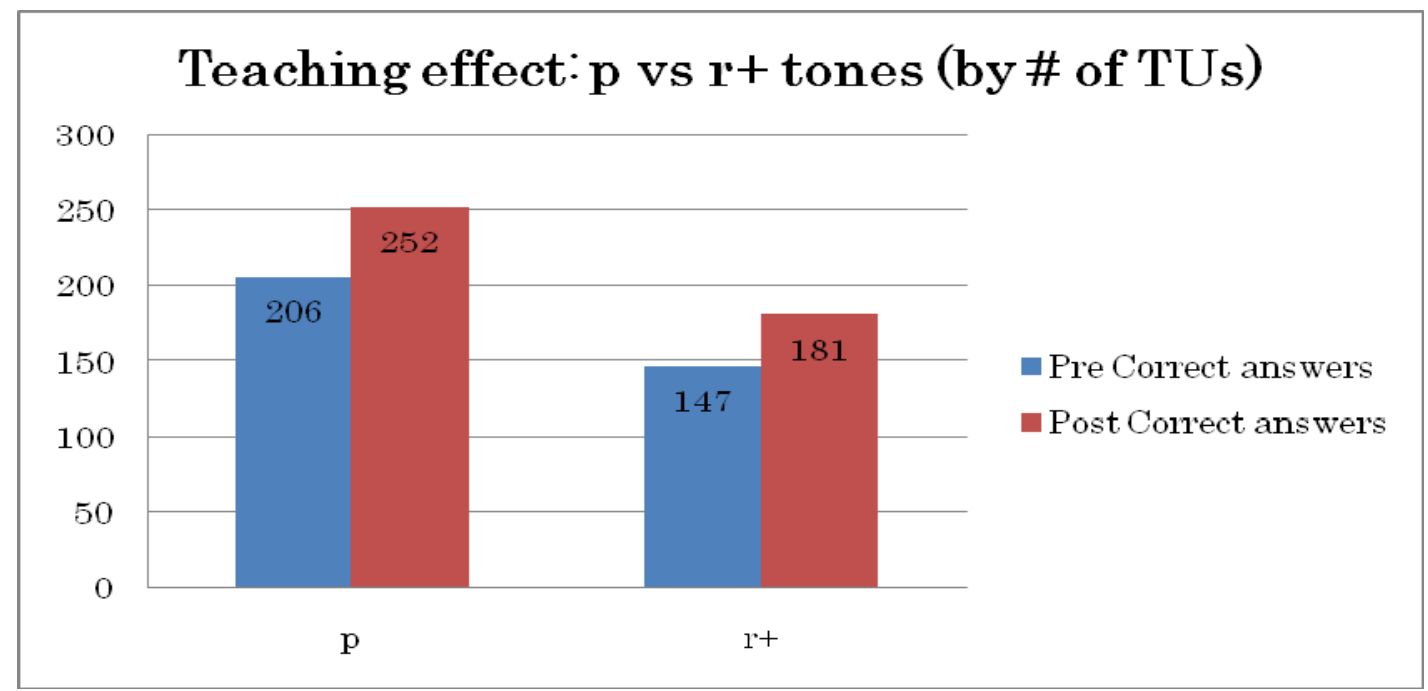

Figure 4. Teaching effect: p vs. r+ tones (counted by the number of TUs). 
Figure 5 is the teaching effect rate compared between p vs. $r+$ tones counted by the number of subjects. The author uses “positive”, “neutral”, and "negative” labels for the teaching effect rate, as in Table 4.

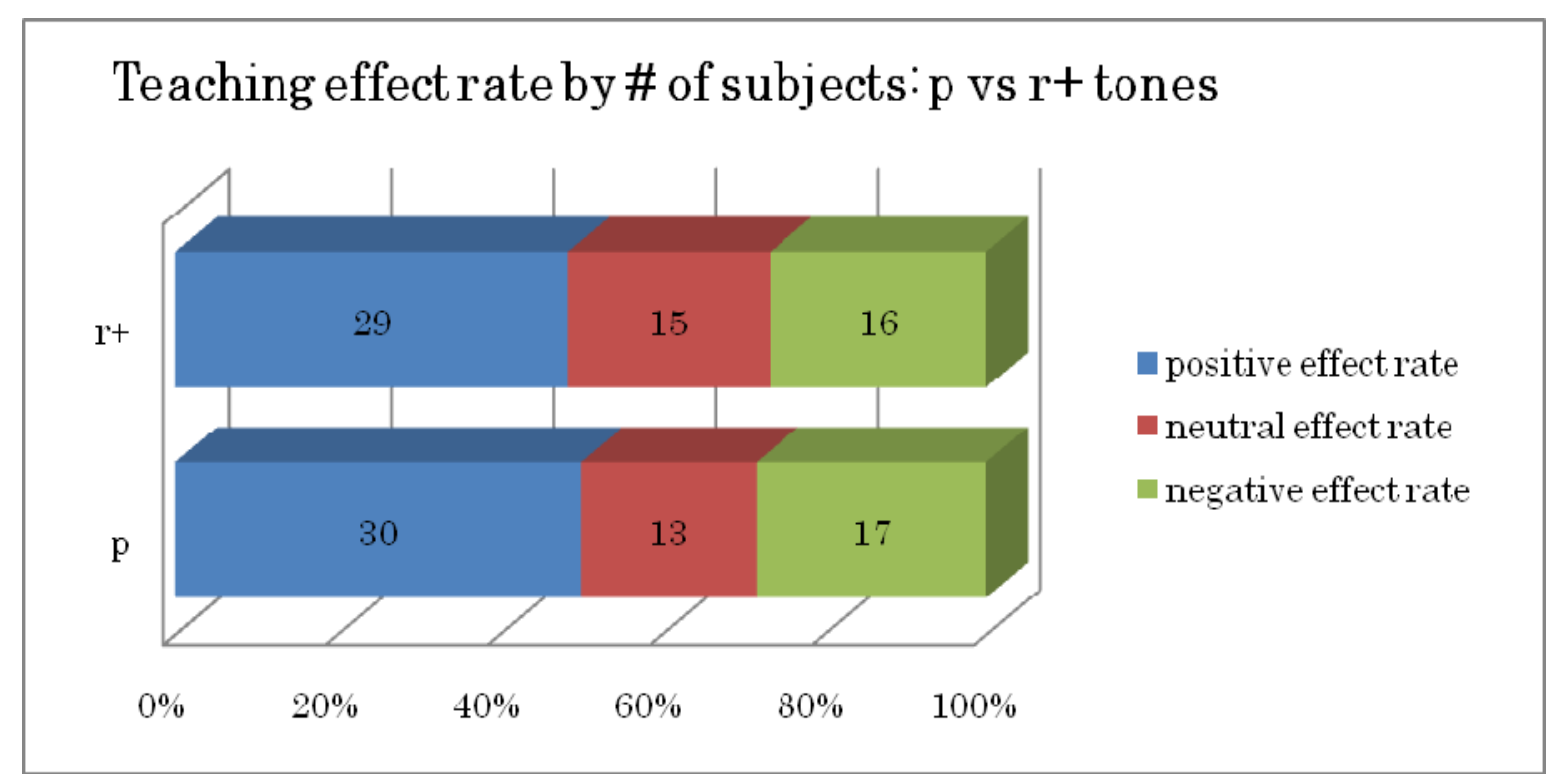

Figure 5. Teaching effect rate: $\mathrm{p}$ vs. $\mathrm{r}+$ tones (counted by the number of subjects).

Figure 5 shows: (1) The teaching effect rate results on p TUs and $r+$ TUs were almost the same; and (2) In both $\mathrm{p}$ TUs and $\mathrm{r}+\mathrm{TUs}$, about half of the subjects showed positive effect (50\% in p TUs, $48 \%$ in $\mathrm{r}+\mathrm{TUs}$ ).

Therefore, from Figures 4-5, even one lesson concentrated on intonation had positive teaching effect in both $\mathrm{p}$ TUs and $\mathrm{r}+\mathrm{TUs}$ in all the valid subjects, and both showed very similar tendencies.

\section{Subjects’ Reactions to the Intonation Lesson}

After this lesson on discourse intonation, the author asked the subjects if they were aware of the functions of intonation in English before the instruction. Forty-four of them gave valid answers as in Table 5.

Table 5

The Subjects' Reactions to the Intonation Lesson

\begin{tabular}{lrc}
\hline Were you aware of the functions of intonation in English? & Valid answers: 44 \\
\hline Not aware & 0 & $0 \%$ \\
Aware but didn't know the details & 38 & $86.4 \%$ \\
Aware but can't distinguish the differences & 5 & $13.6 \%$ \\
Fully aware & 0 & $0 \%$ \\
\hline
\end{tabular}

Table 5 shows the subjects were "aware" of "intonation" as a phenomenon, but did not know "how intonation works”. Examples (1)-(3) represent the subjects' comments after the lesson (translated from Japanese).

Example (1) It is difficult to listen to the differences between the tone choices.

Example (2) I have realised I have been using the tone choices unconsciously.

Example (3) I learned the tone choices make differences in what the speaker means. 


\section{Conclusions}

The result of this study proves it is effective to teach the intonation system in class. The subjects showed a better understanding of the English intonation system after being instructed how differently the five-tone choices function in English speech context. The effect was equally apparent in both $\mathrm{p}$ and $\mathrm{r}+$ tones, and the teaching effect was more obvious in lower-score groups than in higher-score groups. Even though the instruction was only one lesson concentrated on intonation, the result confirms that the author's suggestions in Hosaka (2000) are valid for more effective intonation teaching. However, there was some negative effect shown in the result, further lessons may reduce it over time.

Learners are aware of "intonation", but not likely to be aware that the intonation system they are familiar with (e.g., L1 intonation) is different from that in TL. Hence, it is important to focus on what intonation does rather than what it is (Taylor, 1993). The aim for L2 learners is not learning rules how to use intonation, but developing ability to understand and use intonation in TL appropriately. This is because: (1) The exploitation of intonation in TL can be difficult for L2 learners; and (2) Language transfer from L1 can emerge easily in L2.

As the author suggested in Hosaka (1998), the intonation system has not been overtly taught in English language teaching, particularly in Japan; and needs to be taught more "on how intonation works in natural verbal communication at the discourse level in the target language” (pp. 114-115). This can be done by overt instruction to make L2 learners systematically aware of the intonational differences between their L1 and TL, and between their use in L2 and that of native speakers.

\section{References}

Bradford, B. (1988). Intonation in context. Cambridge: Cambridge University Press.

Brazil, D. (1994). Pronunciation for advanced learners of English. Cambridge: Cambridge University Press.

Brazil, D. (1997/1985). The communicative value of intonation in English. Cambridge: Cambridge University Press.

Brazil, D., Coulthard, M., \& Johns, C. (1980). Discourse intonation and language teaching. London: Longman.

Cruttenden, A. (1979). Language in infancy and childhood: A linguistic introduction to language acquisition. Manchester: Manchester University Press.

Cruttenden, A. (1986). Intonation. Cambridge: Cambridge University Press.

Guernsey, M. (1928). Eine genetische Studie über Nachahmung (A genetic study of imitation). Zeitschrift für Psychologie (Journal of Psychology), 107, 105-178.

Hosaka, H. (1996a). Intonation transfer and foreign accentedness: Comprehensibility in interlanguage (Unpublished M.A. dissertation, Kobe University, Japan).

Hosaka, H. (1996b). Language transfer in English intonation: A cause of foreign accentedness. Kobe Studies in English, 10, 235-266.

Hosaka, H. (1998). Discourse intonation in English and Japanese of Japanese EFL speakers: A pilot study. Annual Review of English Language Education in Japan, 9, 107-117.

Hosaka, H. (2000). Prosody of language learners' speech: In English and Japanese. AILA '99 Tokyo Proceedings CD-ROM, Tokyo.

Hosaka, H. (2004a). L1-L2 intonational contrast at the discourse-lexical level. Dokkyo University Studies in English, 59, 1-15.

Hosaka, H. (2004b). Expanded application of Discourse Intonation Model into Japanese: In comparison with English. Dokkyo University Studies in English, 60, 133-147.

Hosaka, H. (in progress). An investigation of L2 speech in English and Japanese (Ph.D. dissertation, The University of Birmingham, U.K.).

Murata, K. (1968). Yooji no Gengo Hattatsu (Language development of infants). Tokyo: Baifu-kan. 
Nakagawa, K. (1996). Towards the acquisition of Japanese prosody for English native speakers. Hokkai Gakuen University Studies in Culture, 7, 95-118.

Ogura, T. (2005). On'in no hattatsu (Prosody development). In S. Iwatate, \& T. Ogura (Eds.), Yoku Wakaru Gengo Hattatsu (Introduction to language development) (pp. 32-35). Kyoto: Minerva Shoboo.

Suganuma, A. (1993). Gengo Kakutoku Nyuumon (Introduction to language acqusition). Osaka: Osaka Kyooiku Shoboo.

Taylor, D. S. (1993). Intonation and accent in English: What teachers need to know. International Review of Applied Linguistics in Language Teaching, 31(1), 1-21.

Utsu, Y., \& Schaefer, E. J. (1989/2001). Tune in to spoken English (pp. 30-36). Tokyo: Seibido.

Yamato, K. (2000). Validating David Brazil's theory of Discourse Intonation for intonation teaching. Annual Review of English Language Education in Japan, 11, 91-100. 